\title{
Adaptive Bitrate Streaming untuk Peningkatan Kualitas Penerimaan Video pada E-learning
}

\author{
Yeni Anistyasari ${ }^{1}$ \\ ${ }^{1}$ Jurusan Teknik Informatika, Universitas Negeri Surabaya \\ 1yenian@unesa.ac.id
}

\begin{abstract}
Abstrak- Peningkatan kualitas video pada e-learning merupakan topik penelitian yang sedang hangat dibicarakan. Beberapa penelitian tentang video pada e-learning lebih banyak berfokus pada konten. Sedangkan cara pengiriman video kepada pengguna e-learning yang memiliki kualitas sinyal beragam belum banyak diteliti. Penelitian ini mengajukan ide pengiriman video pembelajaran berdasarkan prinsip H.264/SVC dan memanfaatkan karakteristik pengguna e-learning berdasarkan kualitas sinyal yang diperoleh. Tujuan penelitian ini adalah meningkatkan kualitas video yang diterima pengguna e-learning dimanapun berada berdasarkan proportional fairness. Pertama, rumusan masalah dituliskan secara matematis kemudian diselesaikan dengan adaptive bitrate streaming (ABS) sesuai dengan proportional fairnessi berdasarkan algoritma greedy. Simulasi dilakukan untuk menguji kinerja metode yang ditawarkan. Dari hasil simulasi didapatkan bahwa ABS dapat meningkatkan kualitas video yang diterima pengguna e-learning.
\end{abstract}

Kata Kunci- e-learning, adaptive bitrate streaming, video, proportional fairness, algoritma greedy.

\section{Pendahuluan}

Pertumbuhan internet pada satu dekade terakhir ini mendorong pertumbuhan e-learning sebagai media pembelajaran untuk memperkaya pengalaman belajar peserta didik. E-learning digunakan sebagai media untuk berbagi materi pembelajaran, membuat kuliah baru, berkolaborasi dengan peserta didik dan pengajar, membuat dan mengerjakan tugas atau tes, serta penilaian. Saat ini, e-learning telah dimiliki oleh hampir tiap perguruan tinggi sebagai penunjang perkuliahan. Bahkan, e-learning merupakan media pembelajaran utama bagi perkuliahan jarak jauh. Di dalam elearning perguruan tinggi, materi perkuliahan diunggah oleh dosen dan dapat diunduh oleh mahasiswa. Materi perkuliahan dapat berupa teks, audio, dan/atau video.

Bandwidth yang terbatas dan kualitas sinyal yang tidak seragam antar pengguna e-learning menyebabkan penerimaan video kurang memuaskan. Pengguna e-learning yang berada pada area sinyal kuat tidak memiliki masalah dengan kualitas video yang diterima tetapi pengguna yang berada pada daerah sinyal lemah akan terganggu dengan kualitas video yang buruk. Penerimaan kualitas video yang buruk menyebabkan proses belajar melalui e-learning terhambat.

Beberapa penelitian telah membuktikan bahwa video instruksional pada e-learning dapat meningkatkan hasil belajar peserta didik [1]. Kenyataannya, video streaming memerlukan bandwidth yang lebih besar daripada transmisi teks sedangkan bandwidth pada jaringan nirkabel terbatas. Oleh karena itu, diperlukan pengaturan video dan manajemen bandwidth agar dimanapun pengguna e-learning berada dapat menerima video pembelajaran dengan memuaskan.

Beberapa penelitian yang telah dilakukan sebelumnya lebih menekankan pada konten video e-learning. Namun, penelitian yang menekankan pada pemrosesan video dan manajemen scheduling pengiriman video di e-learning masih terbatas [2] [3]. Penelitian yang dilakukan oleh [2] menitikberatkan pada pembagian bandwidth untuk pengiriman lebih dari satu video. Penelitian tersebut menawarkan algoritma untuk sinkronisasi dan pengamatan dua video streaming. Komponen yang dilibatkan yaitu sinkronisasi awal playback, pengamatan playback dua video yang telah disinkronisasikan, koreksi jika sinkronisasi tidak berjalan, dan pengaturan permintaan dua video. Algoritma dikembangkan menggunakan VBScript. Hasil penelitian menunjukkan bahwa sinkronisasi dapat memudahkan transmisi video ke pengguna. Namun, penelitian ini menganggap setiap pengguna memiliki kondisi sinyal yang sama sehingga tidak sesuai dengan keadaan nyata.

Penelitian yang memperhatikan kondisi sinyal pengguna elearning dilakukan oleh [3]. Pada penelitian tersebut, video dikompres menggunakan H.264/SVC sehingga menghasilkan frame I, frame P, dan frame B. Frame I independent terhadap frame lain. Frame $\mathrm{P}$ terikat dengan frame I atau P sebelumnya. Frame B tergantung pada frame I dan P sebelumnya. Oleh sebab itu, frame dependensi perlu diperhitungkan. Video dikirimkan dengan urutan frame I, frame $\mathrm{P}$, dan frame B. Selanjutnya, dilakukan pengaturan bitrate untuk tiap frame. Hasil penelitian tersebut menunjukkan bahwa kompresi menggunakan H.264/SVC dan pengaturan bitrate dapat meningkatkan kualitas penerimaan video bagi pengguna elearning. Kelemahan penelitian tersebut adalah terjadi ketidakadilan bagi pengguna yang berada di daerah sinyal kurang bagus.

Metode pengaturan bitrate untuk pengiriman video selain round robin adalah proportional fairness [4]. Metode ini diawali dengan penyelesaian masalah optimasi menggunakan algoritma greedy untuk mencari bitrate yang paling sesuai untuk alokasi sumber daya pada jaringan nirkabel. Penelitian tersebut membuktikan bahwa proportional fairness greedy memberikan hasil mendekati solusi optimal.

Rumusan masalah pada penelitian "Adaptive bitrate streaming untuk peningkatan kualitas penerimaan video pada e-learning" adalah bagaimana memaksimalkan kualitas video yang diterima oleh tiap pengguna e-learning jika video dikirimkan secara multicast sesuai karakteristik e-learning. Langkah awal penelitian ini adalah membuat rumusan 
masalah secara matematis dengan dengan mengadaptasi [3] dengan menambahkan batasan untuk proportional fairness. Kemudian, rumusan masalah ini diselesaikan dengan algoritma proportional fairness berdasarkan greedy [4]. Simulasi dilakukan pada e-learning dalam jaringan nirkabel 4G. Perangkat yang digunakan adalah Moodle sebagai elearning dan NCTUns Network Simulator and Emulator sebagai simulator jaringan 4G. Kualitas penerimaan video diukur menggunakan Peak Signal to Noise Ratio (PSNR) [5].

Selanjutnya artikel ini dibagi menjadi beberapa bagian yakni Bagian 2 membahas formulasi masalah dan Bagian 3 mengenai metode penyelesaian formulasi masalah. Evaluasi kinerja dan Kesimpulan dibahas di Bagian 4 dan 5.

\section{RUMUSAN MASALAH}

Dalam penelitian ini, jaringan nirkabel diasumsikan menggunakan WiFi dengan akses poin berada di tengah área dan dikelilingi oleh pengguna e-learning yang tersebar secara merata (uniformly distributed). Video akan dikirimkan ke pengguna secara multicast. Sebuah video terdiri dari satu GOP (Group of Pictures) yang terdiri dari beberapa frame I, P, dan B. Hubungan antar frame I, P, dan B dalam satu GOP ditunjukkan Gbr. 1. Frame I, P, dan B dinotasikan sebagai $F_{i}$, $F_{p}$, dan $F_{b}$. Setiap frame memiliki nomor identitas sesuai dengan layer $l$ yang disimbolkan menjadi $l, f$. Kualitas frame video yang diterima diasumsikan sebagai $P$. Dengan demikian, rumusan masalah secara matematis dalam penelitian ini diuraikan pada persamaan (1) - (4).

Tujuan penelitian ini adalah mengoptimalkan kualitas video yang diterima oleh pengguna e-learning (1). Batasan optimalisasi kualitas video dituliskan pada persamaan (2) - (4) $X_{l, f, r}$ bernilai 1 apabila frame $l, f$ diberikan rate $r$ untuk ditransmisikan dan 0 jika sebaliknya. Total waktu pengiriman video tidak diperkenankan melebihi batas waktu maksimal $T_{\max }$. Terakhir, setiap frame $l, f$ hanya diijinkan diberikan maksimal sebuah rate.

Pengukuran kualitas video menggunakan Peak Signal to Noise Ratio (PSNR) yang dirumuskan di persamaan (5) [5]. Diasumsikan resolusi frame video $A \times B$ dan $V(a, b)$ adalah nilai piksel dari frame awal pada posisi $(x, y)$ sedangkan $V^{\prime}(a, b)$ merupakan nilai piksel dari frame setelah diterima pengguna e-learning pada posisi $(x, y) . P_{\max }$ adalah notasi untuk nilai piksel maksimal.

$$
\begin{aligned}
& Q=\sum_{l=1}^{L} \sum_{f=1}^{F} \sum_{r=1}^{R} X_{l, f, r} U_{l, f, r} P S R_{l, f} \\
& \text { s.t } \\
& X_{l, f, r}=\left\{\begin{array}{l}
1, \text { jika framel, } f \text { ditransmiskandenganrater } \\
0, \text { jika framel }, f \text { tidakditransmiskandenganrater }
\end{array}\right. \\
& \sum_{l=1}^{L} \sum_{f=1}^{F} \sum_{r=1}^{R} X_{l, f, r} \tau_{f, r} \leq T_{\max }
\end{aligned}
$$

$$
\sum_{r=1}^{R} X_{l, f, r} \leq 1, l \forall L, f \forall F
$$

$$
\begin{aligned}
& P S N R=10 \log \left(\frac{P_{\max }^{2}}{M S E}\right) \\
& M S E=\frac{1}{A B} \sum_{a=1}^{A} \sum_{b=1}^{B}\left[V(a, b)-V^{\prime}(a, b)\right]
\end{aligned}
$$

\section{ADAPTIVE BITRATE STREAMING}

Sebelum menyelesaikan permasalahan pada persamaan (1) - (4), video dikompresi berdasarkan prinsip H.264/SVC. Setiap frame dibagi menjadi beberapa layer. Layer pertama disebut base layer. Layer di atasnya disebut layer kedua dan seterusnya. Peningkatan kualitas video banding dengan peningkatan layer yang diterima. Kompresi berdasarkan H.264/SVC ditunjukkan pada Gbr. 2

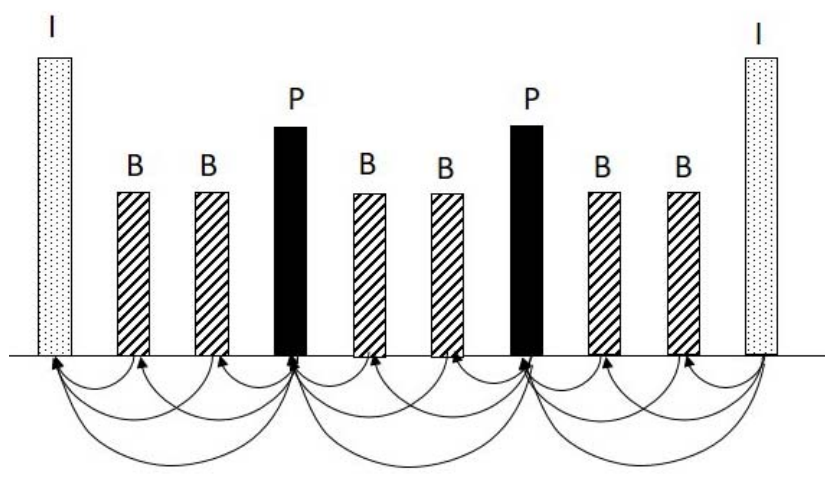

Gbr. 1 Group of Picture

TABEL I

DESKRIPSI SIMBOL

\begin{tabular}{|l|l|}
\hline Simbol & Deskripsi \\
\hline$Q$ & Kualitas video yang diterima pengguna e-learning \\
\hline$L$ & Layer frame video \\
\hline$F$ & Frame video \\
\hline$R$ & Rate video \\
\hline$X$ & Fungsi biner yang bernilai 1 atau 0 \\
\hline$U$ & Jumlah pengguna e-learning yang menerima video \\
\hline$P S N R$ & Nilai PSNR \\
\hline$\tau$ & $\begin{array}{l}\text { Waktu yang diperlukan untuk transmisi sebuah frame } \\
\text { video }\end{array}$ \\
\hline$T_{m a x}$ & $\begin{array}{l}\text { Waktu maksimal yang tersedia untuk pengiriman } \\
\text { video }\end{array}$ \\
\hline$P F$ & Proportional fairness \\
\hline
\end{tabular}


Setelah mendapatkan frame seperti pada Gbr. 2, frame disusun berdasarkan metode Modiste [3], yakni sesuai dengan tingkat ketergantungan sebuah frame terhadap frame lain. Dengan kata lain, frame I lebih penting daripada frame $\mathrm{P}$, frame $\mathrm{P}$ lebih penting daripada frame B. Algoritma penyusunan frame dituliskan di Algoritma 1.

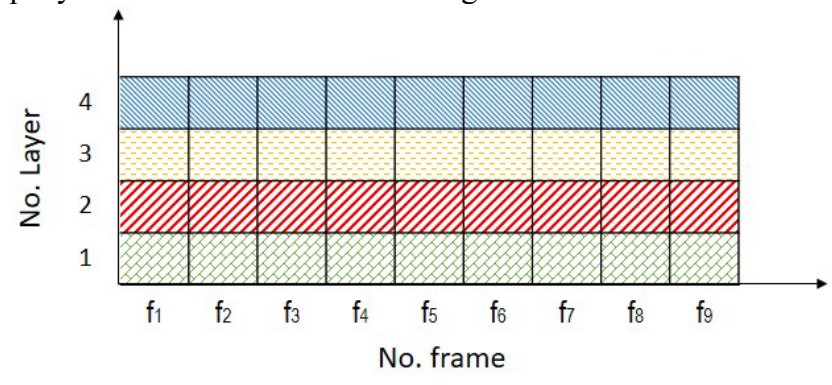

Gbr. 2 Frame dan Layer Video

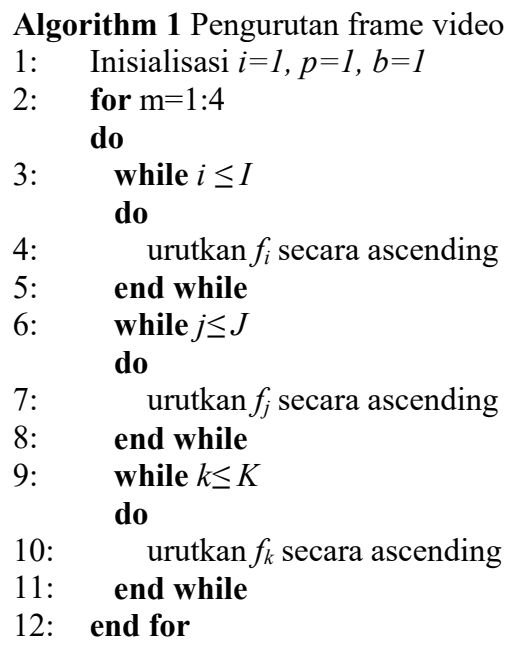

Selanjutnya, setiap frame l,f dijadwalakn untuk ditransmisikan dengan rate $r$ atau tidak ditransmisikan. Metode penjadwalan yang digunakan diadaptasi dari proportional fairness yang berdasarkan metode greedy. Proportional fairness disimbolkan dengan PF. PF harus memaksimalkan jumlah rata-rata rate logaritmis dari pengguna e-learning seperti dituliskan dalam persamaan (7).

$$
P F=\arg \max \sum_{\mathrm{u} \in \mathrm{U}} \log \overline{\mathrm{r}}_{\mathrm{u}}^{\mathrm{r}}(\tau)
$$

Nilai $\tau$ adalah slot waktu. Algoritma penjadwalan mentransmisikan frame video kepada pengguna e-learning dengan nilai terbesar dari

$\frac{\bar{r}_{u}(\tau)}{\overline{T_{u}}(\tau)}$

dimana $\bar{T}_{u}(\tau)$ adalah throughput rata-rata yang dapat diupdate menggunakan exponentially weighted low-pass filter.
$\bar{T}_{u}(\tau+1)= \begin{cases}\left(1-\frac{1}{\tau_{c}}\right) \bar{T}_{u}(\tau)+\frac{1}{\tau_{c}} \bar{r}_{k}(\tau), & k=k^{*} \\ \left(1-\frac{1}{\tau_{c}}\right) \bar{T}_{u}(\tau) & k \neq k^{*}\end{cases}$

dimana $\tau_{\mathrm{c}}$ adalah rata-rata window size.

Nilai rata-rata throughput pengguna $u$ pada slot waktu $\tau$ dapat dituliskan pada persamaan (8). Proportional fairness akan dicapai jika dan hanya jika memenuhi persamaan (9) [4].

$$
\begin{aligned}
& \bar{T}_{u}=\lim _{\tau_{c} \rightarrow \infty} \frac{1}{\tau_{c}} \sum_{\tau=1}^{\tau_{c}} \sum_{n=1}^{N} \rho_{u, n}(\tau) r_{u, n}(\tau) \\
& P F=\underset{s}{\arg \max } \prod_{u \in U}\left(\frac{\sum_{n \in C_{u}} r_{l, f}(\tau)}{\left(\tau_{c}-1\right) \bar{T}_{u}(\tau)}\right)
\end{aligned}
$$

Dari metode yang dituliskan dalam [4], $P F$ akan dicapai jika setiap pengguna e-learning dialokasikan rate yang dituliskan pada persamaan (10).

$$
u^{*}=\underset{r}{\arg \max }\left(\frac{r_{l, f, u}}{\left(T_{\max }-1\right) \bar{T}+\sum_{l}^{L} \sum_{f}^{F} X_{l, f, r} r_{l, f, u}}\right)
$$

Metode greedy yang diterapkan untuk menyelesaikan persamaan (8) terdiri dari tiga langkah yang akan dijelaskan sebagai berikut.

\section{Langkah 1}

Untuk setiap frame $l, f$ hitunglah $r$ yang memberikan hasil

$$
\text { tertinggi dari } \frac{r_{l, f}}{\left(T_{\max }-1\right) \bar{T}+\sum_{l}^{L} \sum_{f}^{F} X_{l, f, r} r_{l, f}}
$$

\section{Langkah 2}

Pilihlah $l, f$ yang memenuhi persamaan berikut ini.

$$
r^{*},(l, f)^{*}=\underset{r}{\arg \max }\left(\frac{r_{l, f}}{\left(T_{\max }-1\right) \bar{T}+\sum_{l}^{L} \sum_{f}^{F} X_{l, f, r} r_{l, f}}\right)
$$

Langkah 3

Ulangi langkah 1 dan 2 hingga semua waktu $\tau$ yang tersedia telah teralokasi. 


\section{IV.HASIL DAN PEMBaHASAN}

Untuk menguji kinerja metode adaptive bitrate streaming yang diajukan, dilakukan simulasi. Selanjutnya, adaptive bitrate streaming dalam penelitian ini disebut ABS. Lingkungan simulasi pada artikel ini diadaptasi dari [3]. Video pembelajaran ditransmisikan dalam jaringan nirkabel WiFi (IEEE 802.11b) yang biasa digunakan di lingkungan perguruan tinggi. Sebanyak 50 pengguna e-learning didistribusikan secara merata dengan jarak maksimum ke akses poin adalah 300 meter. Distribusi pengguna e-learning digambarkan di Gbr. 4.

Video Akito.yuv diunggah pada Moodle. Kemudian, video tersebut dikirimkan secara multicast kepada pengguna elearning yang mengirimkan permintaan terhadap video tersebut.

Kualitas sinyal yang diterima oleh setiap pengguna elearning bergantung pada jarak pengguna ke akses poin. Kualitas sinyal didefinisikan sebagai SNR (Signal to Noise Ratio) [5]. Semakin tinggi nilai SNR, semakin bagus penerimaan sinyal. Tinggi rendahnya SNR dipengaruhi oleh path loss yang dirumuskan $20 \log 4 \pi d / \lambda$ dimana $\lambda$ adalah panjang gelombang dari propagasi sinyal dalam meter.

Hasil PSNR menunjukkan bahwa semakin dekat pengguna e-learning dengan akses poin, semakin besar PSNR yang diterima. Semakin besar PSNR berarti bahwa semakin bagus kualitas video yang diterima. Secara ringkas, semakin dekat pengguna dengan akses poin semakin bagus kualitas video yang diterima. Nilai PSNR untuk tiap pengguna e-learning ditunjukkan di Gbr. 1.

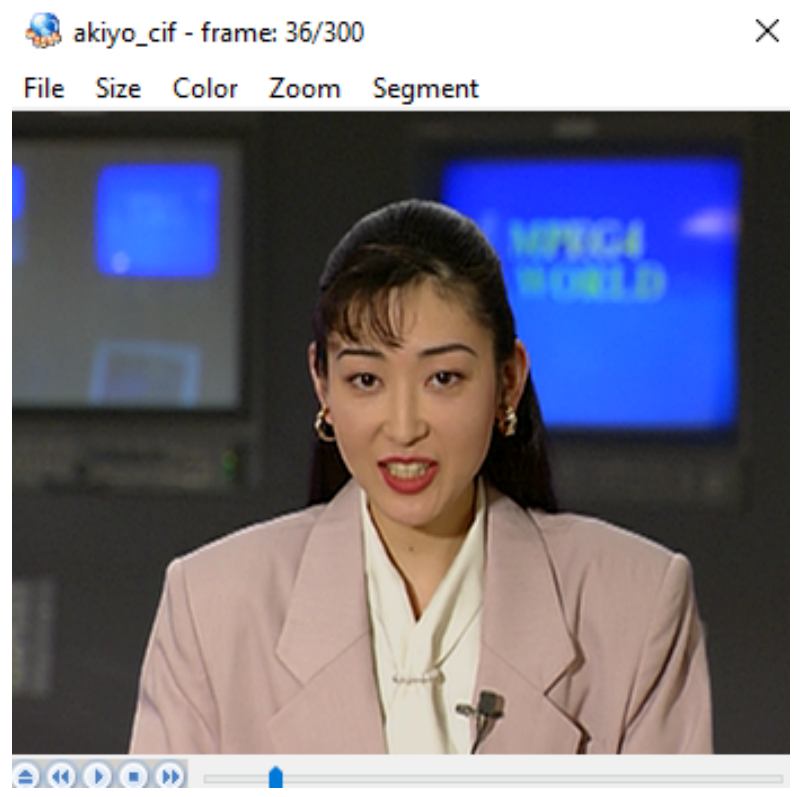

Gbr. 3 Akiyo.yuv

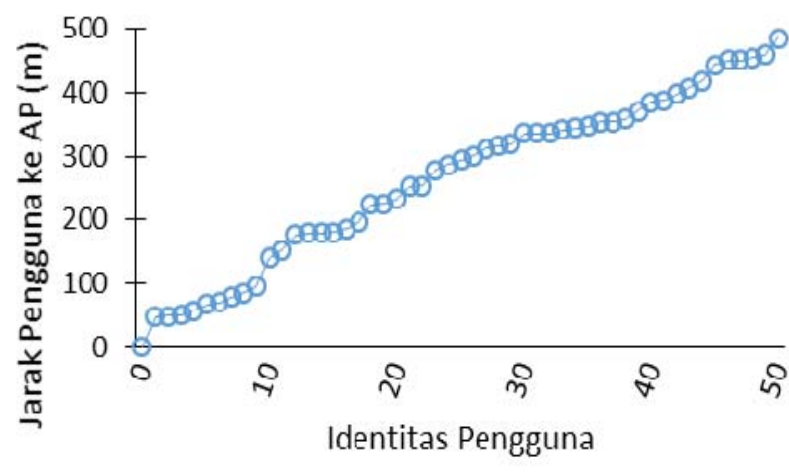

Gbr. 4 Distribusi pengguna e-learning

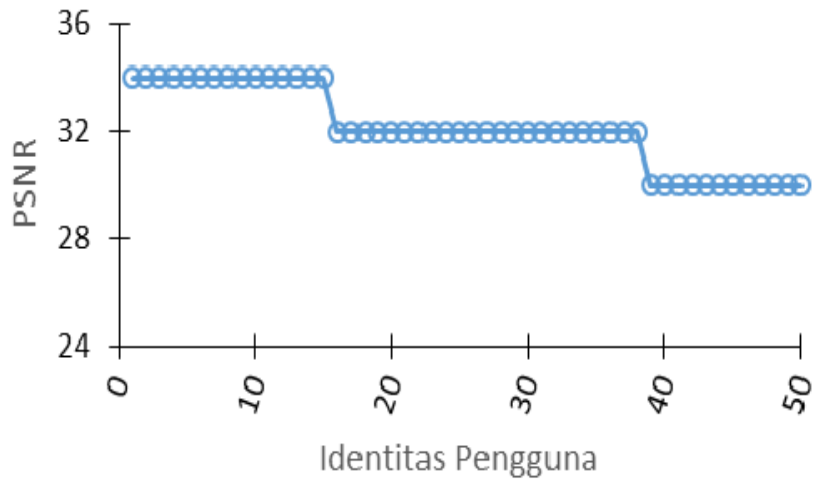

Gbr. 5 PSNR yang diterima pengguna e-learning

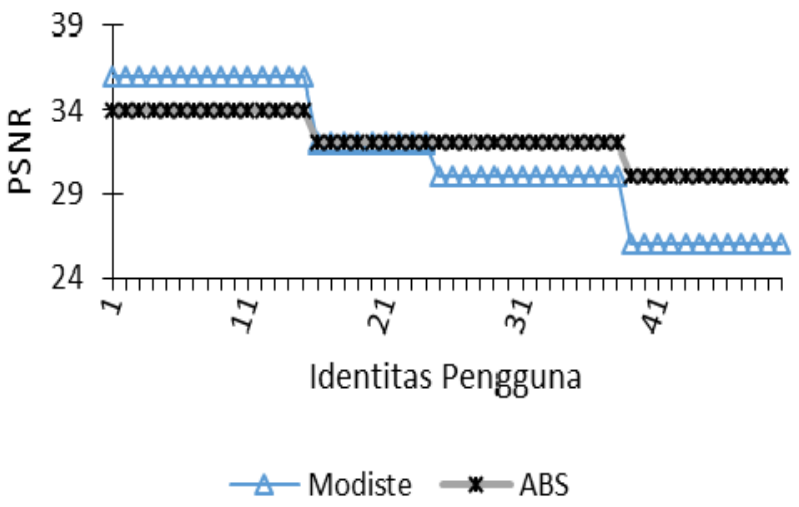

Jika hasil simulasi ABS dibandingkan dengan Modiste, tampak bahwa untuk pengguna e-learning yang berlokasi dekat dengan akses poin, Modiste memberikan hasil lebih baik daripada ABS. Namun, jika dirata-rata ABS memberikan hasil rata-rata PSNR yang lebih baik daripada Modiste. Peningkatan rata-rata PSNR yang diterima pengguna elearning sebesar $30 \%$. Dengan demikian, ABS terbukti dapat mengirimkan video ke pengguna e-learning dengan kualitas rata-rata yang lebih baik daripada Modiste. 


\section{KESIMPULAN}

Masalah yang terjadi pada pengiriman video pembelajaran pada e-learning adalah kualitas video yang diterima oleh pengguna tidak merata akibat kondisi sinyal yang diterima pengguna bersifat heterogen. Oleh karena itu, artikel ini mengajukan solusi pengiriman video pembelajaran secara multicast dengan pengalokasian bitrate untuk setiap video frame. Langkah awal dalam penelitian ini adalah merumuskan masalah secara matematis. Untuk menguji metode yang diajukan, sebuah simulasi dilakukan. Video yang akan ditransmisikan dikompresi berdasarkan prinsip H.264/SVC yakni membagi setiap frame video menjadi beberapa layer. Selanjutnya, frame video diurutkan berdasarkan tingkat ketergantungan dengan frame lain. Setelah frame berurutan, masing-masing frame video dialokasikan sebuah bitrate untuk ditransmisikan. Kualitas video yang diterima oleh pengguna elearning diukur berdasarkan PSNR. Hasil simulasi menunjukkan bahwa metode yang ditawarkan menghasilkan rata-rata PSNR lebih baik sekitar 30\% daripada metode lain yang diajukan oleh peneliti lain.

\section{REFERENSI}

[1] T. Hartsell and S. C.-Y. Yuen, "Video Streaming in Online Learning," AACE J., vol. 14, pp. 31-43, 2006.

[2] K. Kurbel, "Video Streaming Solutions for Web- Based ELearning Courses," pp. 874-877, 2003.

[3] Y. Anistyasari, "Modiste : A Novel Method for Enhancing Video Streaming in E-learning," in Proc. of The

International Conference on Educational Research and Development 2015, 2015.

[4] Z. Sun, C. Yin, and G. Yue, "Reduced-complexity proportional fair scheduling for OFDMA systems," in 2006 International Conference on Communications, Circuits and Systems, ICCCAS, Proceedings, 2006, vol. 2, no. 60472070, pp. 1221-1225.

[5] K. L. Hua, Y. Anistyasari, C. H. Hsu, T. L. Chin, C. L. Yang, and C. Y. Wang, "Multicast scheduling for stereoscopic video in wireless networks," Multimed. Tools Appl., vol. 76, no. 1, pp. 1-28, 2017. 